\title{
A Comprehensive Review on the Prevalence of Vitamin D Deficiency among School- Aged Children around the World
}

\author{
Arti Sureshkumar, Krishna Veni Nagappan* \\ Department of Pharmaceutical Analysis, JSS College of Pharmacy, JSS Academy of Higher Education \& Research, Ooty, Nilgiris, Tamil Nadu, INDIA.
}

\begin{abstract}
Vitamin $D$ is an essential compound for growth and development throughout the human lifecycle. The deficiency of vitamin $\mathrm{D}$ is a major health problem worldwide in all age groups. It maintains normal level of calcium, Phosphorus and provide protection from the diseases and individual's risk of developing, diabetes, multiple sclerosis, lupus, rheumatoid arthritis, heart failure, strokes, hypertension, peripheral vascular disease, coronary heart disease, muscle weakness, respiratory tract infection, skeletal deformities and others. Vitamin D deficiency is more prevalent in countries such as Saudi Arabia, Turkey, Korea, Japan, Canada, England, China, India and Australia. About $90 \%$ of the Vitamin D required for the body function is sourced from sunlight throughout the world. Upon sun exposure body synthesizes pre-vitamin $D$ in the skin, which is then converted into active Vitamin $\mathrm{D}$ in the liver and kidney. In addition, the dietary sources including fish, cod liver oil, egg yolk, milk products are considered as rich sources of Vitamin D. However, an adequate amount of Vitamin D supplementation through dietary sources are not possible; therefore, sunlight exposure along with Vitamin D supplements proportionate to the age for adult and
\end{abstract}

children are suggested by the medical care professionals to overcome Vitamin D deficiency. This review aims to provide an overview of Vitamin D level in various ethnic and geographical origins, including prevalence, causal factors and possible dietary \& supplementary interventions in practice to combat the Vitamin $D$ deficiency.

Key words: Vitamin D deficiency, Prevalence, Fortification, Sources, Functions, Health risks, Worldwide.

\section{Correspondence}

Dr. Krishna Veni Nagappan,

Professor \& Head, Department of Pharmaceutical Analysis, JSS College of Pharmacy, JSS Academy of Higher Education and Research, Ooty-643001, The Nilgiris, Tamil Nadu, INDIA.

Phone: +91 423-2443393

Email: krisath@jssuni.edu.in

DOI: 10.5530/jyp.2021.13.8

\section{INTRODUCTION}

During the nineteenth century, physicians observed a new disease among children who lived in enterprises zone, factory containing districts or urban cities. These children had short growth, crippled legs and the reason behind this was unknown. Later on, this disease was named as rickets and looking past the years, those children had a lack of sunlight exposure because they lived in overpopulated, choked dwelling and small narrow alleys. Deterioration from burning coal and wood, which further reduced the sun rays from reaching the earth caused serve Vitamin D deficiency (VDD) and the result was found to be rickets. ${ }^{1}$ Rickets is manifested as bone pain, weakness, and bone deformities. Rickets was widespread during the $19^{\text {th }}$ century, where the cod liver oil was widely used in the treatment of Rickets. Over time, the role of Vitamin D had been acknowledged in autoimmune diseases, hypertension, cardiovascular diseases, reproductive health, cancer and immune system. ${ }^{2}$

Vitamin D is an essential nutrient that is needed for better health of an individual, with strong and healthy bones and it is traditionally known as sunshine vitamin or anti-rickets factor. ${ }^{3}$ Vitamin D is essential to the body in many other ways such as muscular movement, and transmission of nerve impulses between the brain and other parts of the body. Vitamin $\mathrm{D}$ rich foods include salmon, sardines, egg yolk, shrimp, milk, cereal, yoghurt, orange juice. Also, it is found in liver and fish oil, which is important for the absorption of calcium and prevention of rickets in children and Osteomalacia in adults. ${ }^{4}$ Vitamin D is very important in maintaining the levels of extracellular calcium ions in the body and this helps in the functioning of the metabolic processes, muscular activities ${ }^{5}$ and it is unique as it functions as a hormone because it is synthesized by the body.

In humans, Vitamin D is highly synthesized in the skin through the exposure to ultraviolet (UV) radiation, (specifically radiation of shorter wave-lengths about $315 \mathrm{~nm}$ ). ${ }^{3}$ Other forms of Vitamin D like Vitamin $\mathrm{D}_{2}$ and $\mathrm{D}_{3}$ are available as Vitamin $\mathrm{D}$ supplements. Moreover, Vitamin $\mathrm{D}_{3}$ is produced from lanolin by UV irradiation of 7-dehydrocholesterol. ${ }^{6}$ The Vitamin $\mathrm{D}_{2}$ and $\mathrm{D}_{3}$ namely called as Ergocalciferol and Cholecalciferol originates from fortified, plant, animal foods and other supplements. ${ }^{4}$ Many studies have reported that Vitamin $\mathrm{D}_{3}$ showed more effect than the Vitamin $\mathrm{D}_{2}$ by increasing the amount of serum $25(\mathrm{OH})$ D levels. ${ }^{6}$

VDD causes both skeletal and extraskeletal diseases. ${ }^{6}$ Dietary calcium cannot be absorbed without enough Vitamin D level in the bloodstream. Due to low calcium $(\mathrm{Ca})$ levels, the parathyroid hormone concentration increases in serum causing an increase in the tubular recuperation of $\mathrm{Ca}$ in kidneys and reabsorption from the skeleton at the cost of lowering the bone density. This sort of bone mineralization is mostly seen in children as Rickets. Moreover, Vitamin D is important for its calcium homeostasis and metabolism of minerals in the bone. It is also necessary for its biological functions for differentiation of cells, inhibiting the cell growth and immunomodulation. The best way to increase Vitamin D status is by short, regular exposes of uncovered skin to sunlight. ${ }^{7}$

Some of the Vitamin D facilitated body functions are Cardiovascular functions, Respiratory brain development, and anticancer effect. Vitamin D not only controls the cell growth (normal and cancerous), but it also stimulates the insulin-producing cells in the Pancreas and lowers insulin resistance. Therefore, Vitamin D may help the pancreas for the treatment

This is an open access article distributed under the terms of the Creative Commons Attribution-NonCommercial-ShareAlike 4.0 License, which allows others to remix, tweak, and build upon the work non-commercially, as long as the author is credited and the new creations are licensed under the identical terms. 
of type 2 diabetes. It also affects teeth health, common function of the skin and thus helps in the treatment of skin disorders such as psoriasis and prevent many health problems. ${ }^{6}$

\section{PHYSIOLOGY OF VITAMIN D}

As illustrated in Figure 1, Vitamin D is synthesized in the skin by a process called photolysis where 7 dehydrocholesterol is converted into pre-vitamin $\mathrm{D}_{3}$. Pre-vitamin $\mathrm{D}_{3}$ is synthesized in the epidermis of the skin and it turns into Vitamin $\mathrm{D}_{3}$ or cholecalciferol and then is "ejected" into extracellular fluid space. So Vitamin $\mathrm{D}_{3}$ is primarily bound to the Vitamin D binding protein. ${ }^{8}$ This protein transports the Vitamin D and other nutrients all over the system and then sends it to the liver. Vitamin D can also be consumed through food resources and food supplements. When taken as food, it is absorbed in the intestine and collected by the binding protein, after that it is transported to the liver for further conversion into calcidiol [(25 (OH)D] on hydroxylation. ${ }^{9}$ Further, this gets converted into 1,25-dihydroxy Vitamin $\mathrm{D}_{3}\left(1,25(\mathrm{OH})_{2} \mathrm{D}\right)$ in the kidney and when $1,25(\mathrm{OH})_{2} \mathrm{D}$ is satisfactorily accessible, 24,25-dihydroxy Vitamin $\mathrm{D}\left(24,25(\mathrm{OH})_{2} \mathrm{D}\right)$ is formed in the kidney, which is more catabolized. The $1,25(\mathrm{OH})_{2} \mathrm{D}$ is an active metabolite, goes inside the cell and binds to the Vitamin D receptor. ${ }^{10}$

The $1,25(\mathrm{OH})_{2} \mathrm{D}$ binds to the Vitamin $\mathrm{D}$ Receptor (VDR) which is normally found in most of the tissues and cells in the body. ${ }^{9}$ Many cells also can produce $1,25(\mathrm{OH})_{2} \mathrm{D} \cdot{ }^{11} 25(\mathrm{OH}) \mathrm{D}$ has a vast range of pharmacological activities such as, stimulating insulin production, inhibiting angiogenesis, biological actions, including inhibiting cellular proliferation, terminal differentiation, Renin production and stimulating macrophage cathelicidin production. ${ }^{9}$ These bounded VDRs can stimulate the expression of local genes, functioning responsibly for the synthesis of particular proteins and enzymes for proper body functioning. The most well-known function of $1,25(\mathrm{OH})_{2} \mathrm{D}$ is regulating the balance of calcium and phosphorus for bone mineralization and remodeling. ${ }^{11}$ Vitamin D plays a vital role in making sure that the body and blood have sufficient calcium. Based on the amount of calcium present in the blood, parathyroid will stimulate kidney more for the production of 1 , $25(\mathrm{OH})_{2} \mathrm{D}$ if required. ${ }^{12}$

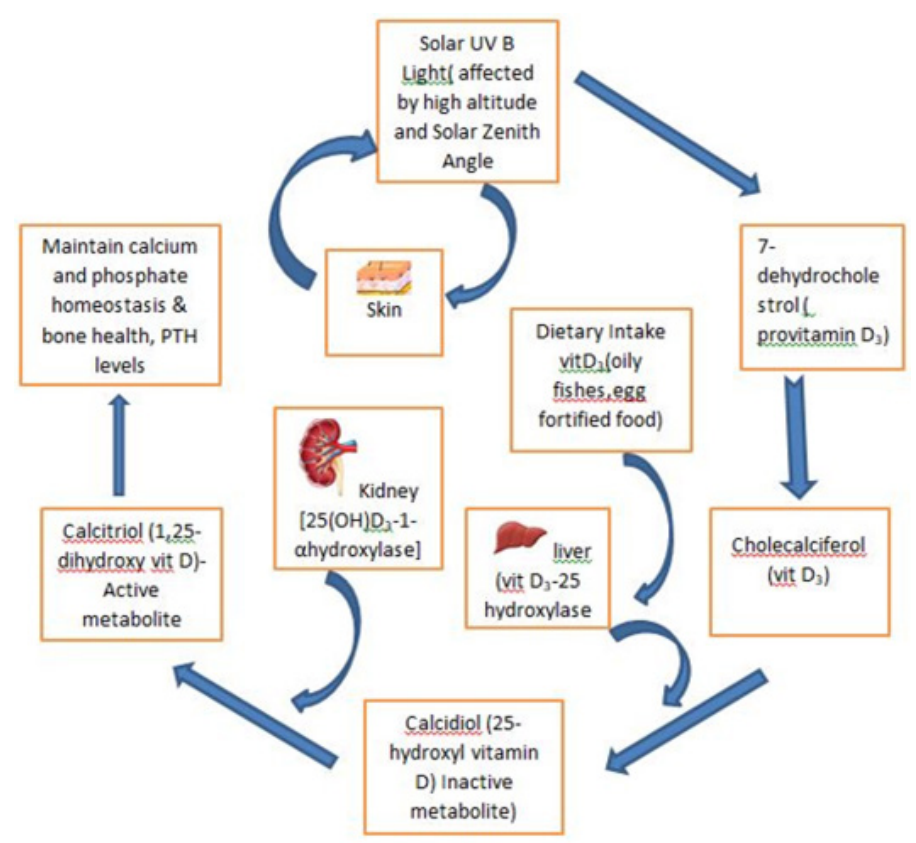

Figure 1: Vitamin D physiology.
More production of $1,25(\mathrm{OH})_{2} \mathrm{D}$ helps to absorb more calcium in the gut from the diet. If the requirement of calcium is not produced then $1,25(\mathrm{OH})_{2} \mathrm{D}$ and parathyroid glands also work together to pull a sufficient amount of calcium from bones if needed. ${ }^{11}$ With an insufficient quantity of Vitamin D, the body might not produce as much required $1,25(\mathrm{OH})_{2} \mathrm{D}$ and may affect the bone health by minimizing the calcium absorption from dietary sources. Bones provide calcium for blood when serum calcium is low. The parathyroid and endocrine glands are located in the neck near thyroid glands. They secrete parathyroid hormone (PTH). PTH regulates serum calcium and phosphate which in return regulates PTH. The kidney produces $1,25(\mathrm{OH})_{2} \mathrm{D}$. After producing $1,25(\mathrm{OH})_{2} \mathrm{D}$ by the kidney, $1,25(\mathrm{OH})_{2} \mathrm{D}$ helps the gut to absorb more calcium than usual and also keeps PTH levels in control. When 1,25(OH) 2 D increases, it helps the body to get accurate calcium balance, which inhibits the secretion of PTH from the parathyroid gland and in turn inhibits the calcium uptake from bones. ${ }^{12}$

\section{CAUSES AND HEALTH RISKS OF VITAMIN D DEFICIENCY}

Children are at greater risk of VDD, if they have limited sun exposure by covering their whole skin, have darker skin tone, and had been breastfed for a long time. VDD in children may also be due to engagement in activities indoor. ${ }^{13}$ Studies have found that children with type 1 diabetes are most likely to have VDD compared with the normal population. ${ }^{4}$ Older people are also at risk of VDD because their skin cannot synthesize Vitamin D efficiently. ${ }^{13}$ Apart from older people, people with obesity, babies and infants of Vitamin D deficient mothers are at a higher risk of VDD. ${ }^{14}$ People with one fat malabsorption syndrome and with the nephritic syndrome are unable to absorb fat-soluble Vitamin D and loses $25(\mathrm{OH}) \mathrm{D}$ bound to the Vitamin D-binding protein in the urine. ${ }^{13}$ Numerous studies have shown that the occurrence of MS (Multiple Sclerosis) and people with Lupus have a higher risk for VDD. ${ }^{4}$ Studies revealed that people with the maximum Vitamin D level had a $24.2 \%$ minor risk of developing rheumatoid arthritis (RA) compared to those with the lowest levels. Besides this, there was a higher rate of VDD among people with Rheumatoid arthritis than in the general population. The activity of RA will worsen as Vitamin D level decrease. Patients with thyroid disease and Hashimoto Thyroiditis also suffer a higher level of VDD. ${ }^{4}$ People with a disability or a chronic disease may limit outdoor activity, therefore their skin cannot synthesize Vitamin D. Some drugs that increase degradation of Vitamin D such as rifampicin and enzymeinducing anti-epileptics: phenobarbitone, carbamazepine, phenytoin will also affect Vitamin D metabolism. ${ }^{15}$

\section{EPIDEMIOLOGY OF VITAMIN D DEFICIENCY WORLDWIDE}

The epidemiological data on the Vitamin D prevalence in various countries are depicted in Figure 2. In Saudi Arabia, VDD status had raised unexpectedly in children and every age group. In girls, VDD is significantly higher than boys. According to different parts of the study, Saudi demonstrated that limited knowledge and less awareness about VDD could be a reason among female students due to covering their body with dark veils for cultural, religious reasons. ${ }^{16}$ In Tehran, the prevalence of VDD was found $91.7 \%$ in $9-12$ years, old students. In a similar study from Isfahan, VDD was $65.2 \%$ among $14-18$ years adolescents. $70 \%$ of adolescent girls in Iran and 80\% in Saudi Arabia have 25(OH) D levels below $10 \mathrm{ng} / \mathrm{mL}$. Another study conducted in Saudi among 12-15 years age girls reported about $81 \%$ possessing $25(\mathrm{OH})$ D levels below 10ng/ $\mathrm{mL} .{ }^{17}$ As per the literature survey in Turkey, VDD is a significant health problem in childhood and adolescent. One of the studies conducted 
in Turkey during the end of summer reported VDD in $23.44 \%$ and insufficiency in $27.75 \%$ population. But by the "end of winter" samples reported a Vitamin D deficient state in $80.36 \%$. VDD was high in winter than summer. ${ }^{18}$ In Korea $\left(34-38^{\circ} \mathrm{N}\right)$ the prevalence of VDD among high school students was 19.6 to $25.4 \% .{ }^{19}$ According to the Ministry of Health and Welfare and the Korean Industry Development Institute, VDD was linked to atopic dermatitis. Children who had Vitamin -D levels under 20 $\mathrm{ng} / \mathrm{mL}$ had a $30 \%$ risk of atopic dermatitis than children whose Vitamin D levels were above $30 \mathrm{ng} / \mathrm{mL} \cdot{ }^{20}$ In England, a study reported that the frequency of VDD was less than 7\% among 1.5 -10 years aged children and then increased to $11-16 \%$ in 11 to 18 years old adolescent. Entirely in the winter time, this became more prevalent. Studies carried out by Absoud et al. reported that British children aged between 4 to 18 years were $35 \%$ Vitamin D deficient. ${ }^{21}$ Watching TV for $2.5 \mathrm{hr}$ or more per day, obesity, minimal physical activities were also considered as the factors for reduced level of Vitamin D. Deficient Vitamin D caused symptomatic rickets in the adolescents as well. ${ }^{18}$

In Japan, according to health insurance claims data from Japan medical data centre (JMDC) rickets patients of age $0-15$ years were reported during 2009-2014. In Hokkaido, a hospital survey for rickets from 1999 to 2004 , reported $9 / 100000$ patients in children aged 4 years. In another study, they found $37.3 \%$ had low serum level of Vitamin D in children residing in Kyoto. ${ }^{22}$ However, in Japan, Vitamin D status was relatively better in the regions in South Asia. Prevalence of hypovitaminosis D $(<30 \mathrm{nmol} / \mathrm{L})$ in women, over 30 years of age was only $10.3 \%$ and inactive elderly $(25(\mathrm{OH}) \mathrm{D}<75 \mathrm{nmol} / \mathrm{L})$ was below $5 \% .{ }^{5}$ The populace of Latin America and the Caribbean region was 556 million in 2006, from varied ethnic origins. Here the rates of hip fracture are 192/100,000 in 50 years aged and older women population. Some studies had reported the status of Vitamin D among young children of various communities and also on accretion matter about hypovitaminosis D in various population of Latin America. Between regions and deficient nutritional status are common and in the poorer regions, food habits showed bountiful variations. ${ }^{5}$ Some high latitude countries such as Canada may be especially sensitive to VDD because of low ultraviolet radiation levels. A cross-sectional survey suggested that as many as three million Canadians had inadequate Vit-D levels and 1.1 million Canadians are Vitamin D deficient. ${ }^{23}$ Canadian health measure survey analyzed data from children aged 3-18 years who participated in a survey conducted during 2012- 2013. In all children, $5.6 \%$ were Vitamin D deficient, and $71 \%$ were Vitamin D sufficient. ${ }^{24}$ In Toronto, between the years 1988 and 1993 Kooh and Binet reported, that there were 17 cases of clinical Vitamin D deficiency rickets among 7 to 33 years age group and when supplemented with Vitamin D, all recovered. ${ }^{25}$ In China, Huzhou Maternal and Child Care hospital conducted a survey and reported that from January 2012 to August 2015, about 23\% of

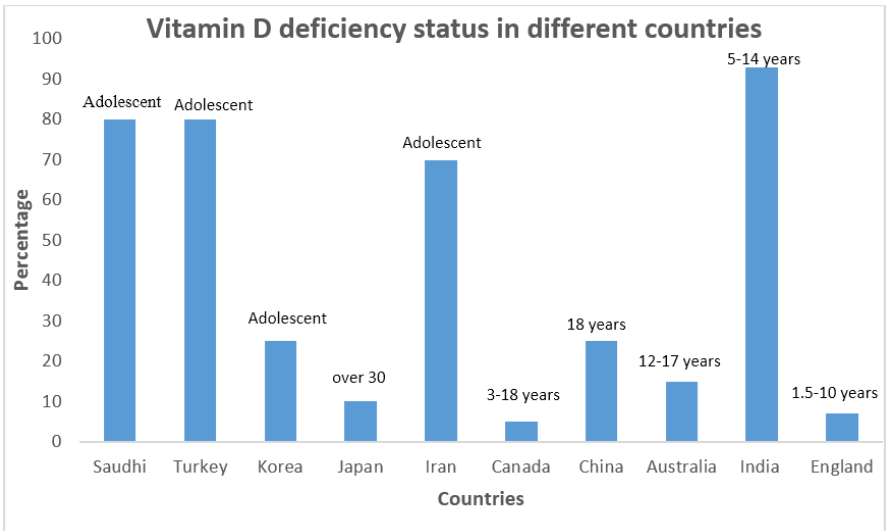

Figure 2: Vitamin D deficiency in various countries. children under 18 years of age were Vitamin D deficient, and 76.7\% were Vitamin D sufficient status. VDD was $29.7 \%$ in winter, $23.4 \%$ in spring, which was higher than in summer and autumn $(21.4 \%$ and $19.9 \%$ respectively). Children aged 1 to 17 years are prone to VDD and insufficiency. ${ }^{26}$

In China, the prevalence of VDD increase in spring and winter, compared to autumn. Foo et al. reported that in Beijing, China (Latitude $40^{\circ} \mathrm{N}$ ) the level of Vitamin D among adolescent girls participating in sports was found to be $14.4 \mathrm{ng} / \mathrm{mL}$ and when not participating in sports, Vitamin D levels was $12 \mathrm{ng} / \mathrm{mL} .^{27,28}$

The status of VDD showed a high variation in different European countries. In Greece, $47 \%$ of adolescents showed Vitamin D deficient. Serum $25(\mathrm{OH}) \mathrm{D}$ was lower than $25 \mathrm{nmol} / \mathrm{L}$ in winter. According to Hoorn study, the determinants to assess Vitamin D status in the Netherlands were as follows- time spent outdoors, consumption of fatty fish, body mass index, margin and consumption of Vitamin D supplements. ${ }^{29}$ One of the studies reported that VDD was more prevalent in southern Europe than northern Europe. ${ }^{5}$ In Australia, a longitudinal cohort study conducted in Adelaide between 2008 to 2010 by Tiffany K Gill et al. had reported that the South Australian population is prevalent with VDD. Accordingly physical activity and diminution of obesity may help to increase Vitamin D levels. ${ }^{30}$ From 2011 to 2012 Australians health survey found that $23 \%$ Australian adults were Vitamin D deficient $(<50$ $\mathrm{nmol} / \mathrm{L}$ ), among them, $17 \%$ are slightly deficient $(30-49 \mathrm{nmol} / \mathrm{L}$ ), and $6 \%$ are moderately deficient (13- $29 \mathrm{nmol} / \mathrm{L}) .{ }^{15}$ According to Australian health survey (Australian Bureau of Statistics), children had low levels of Vitamin D in 2011-2012. 12 to 17 years aged children were $15 \%$ Vitamin D deficient, with similar rates for boys (15\%) and girls (16\%). Moreover, Vitamin D level considerably varied by season, which was less in summer (14\%) and high in winter (36\%). Vitamin D production can also be affected by physical characteristics, for example, people with darker skin produced less Vitamin D. ${ }^{7}$

Usually, sun protection was not needed in winter and late autumn in some parts of Australia where the UV index was below 3. Moreover, it is vital to balance the need for sun exposure to produce adequate Vitamin $\mathrm{D}$ and also avoid the risk of skin damage from too much exposure when the UV index is above $3 .^{31}$ Few studies demonstrated that $25(\mathrm{OH}) \mathrm{D}$ levels are directly related to the period of contact with sunlight. This may be a reason for improved Vitamin D level among the rural population who were agriculture employees having their chest exposed to sunlight when compared to the urban population. Exposure of sunlight had a positive effect on Vitamin D status. ${ }^{11}$ Studies revealed that children in the age group of 9 months to 5 years showed the prevalence of VDD (46-80 \%) and seasonal deviation was observed among $41.6 \%$ preschool children. ${ }^{32}$

In northern India, Kashmir valley had low 25(OH) D levels. ${ }^{11}$ Some factors which change the Vitamin D levels are as follows: atmospheric pollution, geographic location, time of the day, cloud cover. Among them solar zenith angle is essential and it is the angle between the zenith and centre of the sun. It fluctuates with the time of the day, season and geographic location. ${ }^{11}$ Prevalence of VDD among 5-20 years children varied from $37.8 \%$ to $97.5 \%$. Among rural adolescent girls, the seasonal variation had also been reported with an expression of low Vitamin D levels at a latitude of $26^{\circ} \mathrm{N} .{ }^{32}$ These results have established that VDD occurs not only in high latitude but also in lower latitude countries with ample sunshine. This was possible due to avoidance of sunlight, indoor lifestyles, clothing coverage and sunscreen use, adiposity and low dietary intake of Vitamin D rich foods or supplements. Another dietary factor, which may contribute to the improvement of VDD, is low calcium diet which, increased secondary hyperparathyroidism. and reduce the levels of $1,25(\mathrm{OH})_{2} \mathrm{D} \cdot{ }^{33}$ Studies found that unprivileged toddlers of a slum area 
in Pune (India) with lack of sunlight had a higher rate of hypovitaminosis $\mathrm{D}$ when compared to toddlers in slum exposed to sunlight. ${ }^{32}$ Another study which was conducted in Kolkata, West Bengal by Baidya et al. found $92.5 \%$ to be VDD. ${ }^{34}$ Despite more fish intake, (fish contains a rich source of Vitamin D), the residents of Bengal suffer poor Vitamin D status compared to rest of the Indians. ${ }^{6}$ Studies carried out in Maharashtra and different parts of India, have shown a high prevalence of Vitamin D deficiency in adolescents, School girls and college students. ${ }^{3,33,35}$

\section{PROBLEMS DUE TO VITAMIN D DEFICIENCY}

Children and adults who are suffering VDD and rickets are more likely to get cough, cold or upper respiratory tract infection. Insufficiency of Vitamin D leads to bone pain and muscle weakness associated with cardiac failure, stroke, hypertension, peripheral vascular disease, coronary artery disease. Studies demonstrated that Vitamin D plays a vital role in brain function and development, regulation, and a healthy nervous system. VDD was familiar in patients with Parkinson's disease and older adults with cognitive decline. Children, who had fewer minerals in their skeleton, had resulted in a variety of skeletal deformities. This causes muscle weakness, and sometimes children face difficulty in standing and walking. Also, the elderly had more frequent falls, thereby increasing their risk of fracture. ${ }^{13}$ Being "D-deficient" may increase the risk of a host of chronic diseases, such as osteoporosis, heart disease, some cancers, and multiple sclerosis as well as infectious diseases such as tuberculosis and even the seasonal flu. ${ }^{4}$ VDD is the reason for abnormalities in calcium, phosphorus and bone metabolism. It also decreases the absorption of dietary calcium and phosphorus, increasing PTH levels and the PTH- mediated increase in osteoclastic activity. Therefore osteoplastic activity forms local foci of bone weakness and causes a generalized decrease in bone mineral density, which created osteopenia and osteoporosis (BDM). ${ }^{13}$ The intestine typically absorbs $10-15 \%$ of dietetic calcium in Vitamin D deficient condition and 30\% from the diet in Vitamin D sufficient state. During periods of growth and pregnancy approximately $60-80 \%$ can be consumed with more requirements of calcium. Studies showed that serum $25(\mathrm{OH}) \mathrm{D}$ levels greater than $30 \mathrm{ng} /$ $\mathrm{mL}$ is needed to prevent the secondary hyperparathyroidism-induced skeletal condition and for expanded intestinal calcium absorption. ${ }^{36}$ Numerous studies found that VDD is related to cancer, autoimmune diseases, diabetes mellitus, sudden cardiac death, stroke, heart failure, overall cardiovascular death. Some observational studies clarified that colon and other cancers are also related to VDD.

The poor generally suffer from malnutrition as Vitamin D rich dietary sources are minimal and expensive to most people. ${ }^{6}$ High prevalence of VDD was reported all over India, in healthy kids, adolescents, young adults and people above 50 years age. The government of India has initiated many schedules to prevent malnutrition in infants and children. The two main programs are integrated child development scheme (ICDS) and the Mid-day meal (MDM). State-sponsored programs aim to address education, health, nutrition and social equity issues of underprivileged children. ${ }^{36}$ Another programme sponsored by Rajasthan government is the Integrated Food Fortification Programme (IFFP), which is fortifying around 8,900 metric tonnes of oil, 41,000 metric tonnes of milk and more than 4,500 metric tonnes of wheat flour every month and reaching about 15 million people. These foods fortified with micronutrients such as iron, folic acid, Vitamin $B_{12}$, Vitamin A, and Vitamin B, helps to improve the public health and are distributed through both market and government distribution channels. ${ }^{37}$

\section{FORTIFICATION OF FOOD WITH VITAMIN D}

Food fortification is the procedure of adding essential nutrients to food for prevention, and correction of demonstrated insufficiency of one or more nutrients in particular people. This is a safe and successful way to improve public health and has been used around the world since the 1920s. Food fortification with Vitamin D is a suitable way of getting better Vitamin D levels among common public. Generally, traditionally Vitamin D food fortification is known as "Bio-addition." Bio-addition of Vitamin D also known as "Biofortification" refers to many ways of improving Vitamin D content in food without the explicit exogenous accumulation of Vitamin D., For example, the addition of feeding hens with Vit-D will improve the Vitamin D content in eggs. To increase Vitamin D content in the flesh of farm fishes, they were fed with food containing Vitamin D content to fishes. ${ }^{38}$ Staple food such as wheat flour, maida, rice, rice flour is considered as perfect vehicles for Vitamin $\mathrm{D}$ fortification. Butter, ghee, oil, other spreads, milk, yoghurt, infant formulas, whole milk, skim milk, and double toned milk could be equipped with Vitamin D. ${ }^{39}$ In Indian general market, only procured milk from an Indian dairy co-operative, is fortified with $150 \mathrm{mg}$ calcium, $4.5 \%$ fat, $75 \mu \mathrm{g}$ Vitamin A and $0.5 \mu \mathrm{g}$ Vitamin D, per $100 \mathrm{~mL}$ and can be used up to 120 days, if the box is not opened. However, the content of Vitamin D was decreased at $4^{\circ} \mathrm{C}$ and much Vitamin $\mathrm{D}$ is not left by 120 days. $^{2}$ As per the survey, the demand for this product was deficient. Kellogg's cereal which is fortified with Vitamin D is also available which is expensive for low-income group. ${ }^{6}$

\section{SOURCES OF VITAMIN D}

Contact with natural sunshine (Solar UV-B, Wavelength 290- $315 \mathrm{~nm}$ ) is a significant supply of Vitamin D. ${ }^{3}$ One of the studies conducted in 2004 and Michael F Holick reported that above 90\% of the Vitamin D requirement comes from casual exposure to daylight for many people and human skin had a large capacity to produce Vitamin D. Egg yolk, butter, juice, yoghurt, nutritional supplements, and fortified food are the wealthy sources of Vitamin D. ${ }^{3}$ Whilst, the milk contains several nutrients and Vitamins, it is not regarded a major source of Vitamin D and likewise it is present in small quantities in vegetables. ${ }^{39}$ As shown in Table 1. oily fishes such as sardines, salmon, mackerel, and fish oil such as cod liver oil are essential sources of Vitamin D. ${ }^{3}$ The content of Vitamin D in fish is unaffected if it is baked but reduced to almost $50 \%$ in fried fishes. Compared to wild salmon, the content of Vitamin D is only $25 \%$ in farm-raised salmon. Fortified food items with Vitamin D like cereals, some yoghurts, margarine, and yeast are available in some of the western countries such as the United State of America and United Kingdom. ${ }^{3}$ Soy chunks, Tofu, and Mushroom are the healthy source of Vitamin D. Orange juice is rich in Vitamin D as well as in calcium. The daily requirements of Vitamin D among children are provided in Table 2. People with shady skin have natural sun protection and requires 3 to 5 times longer exposure to have an equal quantity of Vitamin D as a person with a white skin tone. ${ }^{10}$ Vitamin $\mathrm{D}$ is available in two forms: Vitamin $\mathrm{D}_{2}$ (ergocalciferol) from plant sterol, ergosterol and irradiation of the yeast, and Vitamin D3 (cholecalciferol) from oily fish, cod liver oil and produced in the skin. ${ }^{36}$

\section{FUNCTIONS OF VITAMIN D}

Vitamin D is one of the micronutrient in our body to stay healthy. It helps the body in,

- Absorbing the calcium building strong and healthy bones.

- Blocking the discharge of parathyroid hormone that reabsorbs the bone tissue and converts bone-thin and brittle.

- Also, Vitamin D plays a role in muscle function and immune system. 
Table 1: Vit-D content of food (calcium and Vitamin D).

\begin{tabular}{cccc}
\hline S. NO & Vitamin D & Serving size & Food \\
\hline 1. & $1360 \mathrm{IU}$ & $1 \mathrm{Tbsp}$ & Cod liver oil \\
2. & $400-800 \mathrm{IU}$ & $3 \mathrm{OZ}$ & Salmon wild caught \\
3. & $425 \mathrm{IU}$ & $3 \mathrm{OZ}$ & Catfish \\
4. & $230-245 \mathrm{IU}$ & $3 \mathrm{OZ}$ & Tuna (canned in oil) or \\
5. & $90-125 \mathrm{IU}$ & $1 \mathrm{Cup}$ & Mackerel \\
\hline
\end{tabular}

Table 2: Daily requirement of Vitamin $D$ among various age groups: Institution of medicine. ${ }^{8}$

\begin{tabular}{ccc|} 
S. No & Age & Vit-D requirement/Day \\
\hline 1. & 1 to 3 years & $600 \mathrm{IU}$ \\
2. & 4 to 8 years & $600 \mathrm{IU}$ \\
3. & 9 to 18 years & $600 \mathrm{IU}$ \\
4. & 19 to 49 years and & $600 \mathrm{IU}$ \\
5. & Women over 51, men over 71 & $600-800 \mathrm{IU}$ \\
6. & Individuals with osteoporosis & $800 \mathrm{IU}$ \\
7. & pregnant and breastfeeding & $800 \mathrm{IU}$ \\
\end{tabular}

- Vitamin D helps recycle calcium in the kidneys so bones can reabsorb it. If this did not happen, the body would lose more of Vitamin D through urination.

- Absorption of calcium from a healthy diet and other calcium supplements.

- During the period of pregnancy, when foetal bones are promoting calcium is deposited into bones, making them healthy. This is how Vitamin D performs an essential role. Vitamin D is demanded for healthy metabolism and utilization of calcium. It also aids in the mineralization of bone. During pregnancy, maternal Vitamin D requirements can increase up to 4 to 5 folds to facilitate the availability of the extra calcium required for the foetal skeleton growth. In children, enough Vitamin D levels are necessary for the healthy development of bones and teeth. It is needed in both children and adults, to manage muscle weakness, normal blood clotting and healthy thyroid function.

- Vitamin D also exhibits several non-skeletal effects, principally on the immune, endocrine and cardiovascular system. Vitamin D can regulate cell differentiation and growth by binding to the Vitamin D receptor, found in most body cells.

- Various observational investigations record inverse associations between Vitamin D status and susceptibility of autoimmune disease, diabetes mellitus and systemic lupus erythematosus. ${ }^{36}$

- The Vitamin D Receptor is expressed by the most cells of the immune system, including regulatory $\mathrm{T}$ cells and antigen-presenting cells and macrophages.

- Under the condition of increased insulin demand, di-hydroxy Vitamin D has a vital role in insulin secretion. ${ }^{36}$

\section{PURPOSE OF THE STATUS OF VITAMIN D DEFICIENCY IN SCHOOL GOING AGE CHILDREN}

Regarding bone density and skeletal development, adolescent and childhood are the crucial periods. During childhood and adolescent, nearly $40 \%-60 \%$ of entire skeletal mass at maturity is gathered. ${ }^{6}$ Besides this physical activity, genotype, diet, and sufficient Vitamin D levels are significant factors for gaining the optimal bone mass. There are many factors which affect Vitamin D levels such as sun exposure, skin pigmentation, clothing style, the latitude of region, dairy products consumption, fish and Vitamin D supplementation. The study of Vitamin D status among children helps in determining the risk factors of VDD and also helps to improve the health of school-age children by the supplementation with

- Vitamin D rich cod liver oil.

- Twice a week, spending 5 to $30 \mathrm{~min}$ in the sun without sunscreen.

- Eating natural foods such as cheese, yoghurt, egg yolk, and flesh of fatty fish containing Vitamin D.

- Vitamin D supplementation.

- Mushrooms are rich in Vitamin $\mathrm{D}_{2}$. From UV sunlight, mushrooms are a rich source of Vitamin D.

- Almond milk with over 100 IU of Vitamin D. It is always a healthy option to cow milk.

- Dairy products, fortified soymilk, and margarine, fatty fish are the primary source of Vitamin D.

Children who have grown with a healthy diet will be healthy, active and strong, also they are likely to become more healthy adults. Children have begun to acknowledge not as whom they are today though for their future roles in creating families, powering, the work face and shaping democracy work. The quantity of food intake in children is quite lesser when compared to adults. Therefore children need dense-energy and dense micronutrients including Vitamin D. ${ }^{40}$ Daily a child's body requires calcium between $700 \mathrm{mg}$ and adolescent requires $1300 \mathrm{mg} /$ day. Children require both Vitamin $\mathrm{D}_{2}$ and $\mathrm{D}_{3}$ to maintain a healthy body and to help in the absorption of calcium and phosphorus from the diet into the bloodstream, which aids extensively in building and maintaining strong bones. Severe, Vitamin D insufficiency may lead to rickets, with delayed motor development, muscle weakness, quick fracture due to fall and soft skull or leg bones. They may also complain about bone pains, muscle weakness.

\section{CONCLUSION}

An adequate amount of Vitamin D production by only dietary sources is not possible. Therefore, sufficient sunlight exposure along with Vitamin D supplementation according to age for children and adults, to prevent VDD is suggested worldwide. Although for numerous reasons even those parts, where the sunlight is reachable, VDD is highly prevalent, Including the Middle East, India, Columbia, Mexico, Brazil, and Australia. This review aims to avert the numbers of health problems, caused by VDD. Therefore, the Indian government needs to take fundamental steps in this path. At the national level, population-based programmes should be developed to increase awareness of the problem to provide affordable Vitamin D supplements and also to provide food which is Vitamin D fortified to the needy people. To prevent the VDD status in India, intense research, field study with effective collaboration with the government, health care personnel, consumers and industries are essential.

\section{ACKNOWLEDGEMENT}

The Authors acknowledge the support of JSS AHER, Mysuru and JSS College of Pharmacy, Ooty for providing the facilities to carry out the work.

\section{CONFLICT OF INTEREST}

The authors declare that there is no conflict of interest. 


\section{ABBREVIATIONS}

VDD: Vitamin D deficiency; VDR: Vitamin D Receptor; 25(OH)D: 25 Hydroxy Vitamin D; 1, $25(\mathbf{O H})_{2}$ D: 1,25 Di Hydroxy Vitamin D; 24, 25 $(\mathrm{OH})_{2}$ D: 24, 25 Di Hydroxy Vitamin D.

\section{REFERENCES}

1. Feldman D. Chapter 56 -The Role of Vitamin D in Orthopedic Surgery. $4^{\text {th }}$ Edition ed: Academic Press. 2018.

2. Singh A, Atta A, Gupta A, Mengi S, Malhotra P. Vitamin D: Pathophysiology of its Deficiency. JIMSA. 2014;27(4):224-5

3. Suchanda G, Yadav KS, Gomes MW. Vitamin D status in Indian population: Major Health Concern. World J Pharm Res. 2016;5(1):362-78.

4. Lhamo Y, Chugh PK, Gautam SR, Tripathi CD. Epidemic of Vitamin D deficiency and it Management: Awareness among Indian Medical Undergraduates. J Environmental Public Health. 2017;1-7.

5. Mithal A, Wahl DA, Bonjour JP, Burckhardt B, Dawson-Hughes B, Eisman JA, et al. Global Vitamin D status and determinants of hypovitaminosis D. Osteoporos Int. 2009;20(11):1807-20.

6. Gupta A. Vitamin D deficiency in India: prevalence, causalities and interventions. Nutrients. 2014:6(2):729-75.

7. Webb AR. Who, what, where and when-influences on cutaneous Vitamin $D$ synthesis. Prog Biophys Mol Biol. 2006;92(1):17-25.

8. Battault S, Whiting SJ, Peltier SL, Sadrin S, Gerber G, Maixent JM. Vitamin D metabolism, functions and needs: From science to health claims. Eur J Nutr. 2013;52(2):429-41.

9. Holick MF, Binkley NC, Bischoff-Ferrari HA, Gordon CM, Hanley DA, Heaney RP, et al. Evaluation, treatment, and prevention of Vitamin D deficiency: An Endocrine Society clinical practice guideline. Endocrine Society. 2011;96(7):1911-30.

10. Lips P. Vitamin D Physiology. Prog Biophys Mol Biol. 2006;92(1):4-8.

11. Harinarayan CV, Joshi SR. Vitamin D status in India-its implications and remedial measures. J Assoc Physicians India. 2009;57:40-8.

12. Levine BS, Rodriguez M, Felsenfeld AJ. Serum calcium and bone: Effect of PTH, phosphate, Vitamin D and uremia. Nefrologia. 2014;34(4):658-69.

13. Nair R, Maseeh A. Vitamin D: The "sunshine" Vitamin. J Pharmacol Pharmacother. 2012;3(2):118-26.

14. Chang SW, Lee HC. Vitamin D and health: The missing Vitamin in humans. Pediatrics Neonatol. 2019;60(3):237-44.

15. Taylor R, Beggs S, Harrison R, Savenake J, Denholm J, Trainer E. Low Vitamin D in Tasmania: Key health messages for doctors, nurses, pharmacists and allied health professionals. 2014

16. Al-Saleh Y, Al-Daghri NM, Khan N, Alfawaz H, Al-Othman AM, Alokail MS, et al Vitamin D status in Saudi school children based on knowledge. BMC Pediatr. 2015;15(53):2-16

17. Neyestani TR, Hajifaraji M, Omidvar N, Reza EM. High prevalence of Vitamin D deficiency in school-age children in Tehran, 2008: A red alert. Public Health Nutr. 2011;15(2):324-30

18. Erol M, Ozgul Y, Kucuk SH, Gayret OB. Vitamin D Deficiency in Children and Adolescents in Bağcılar, İstanbul. J Clin Res Pediatr Endocrinol. 2015;7(2):134-9.

19. Kim SH, Oh MK, Namgung R, Park MJ. Prevalence of 25-hydroxy Vitamin D deficiency in Korean adolescents: Association with age, season and parental Vitamin D status. Public Health Nutr. 2012;17(1):122-30.

20. Vestita M, Filoni A, Congedo M, Foti C, Bonamonte D. Vitamin D and atopic dermatitis in childhood. J Immunol Res. 2015:257879.

21. Absoud M, Cummins C, Lim M, Wassmer E, Shaw N. Prevalence and Predictors of Vitamin D Insufficiency in Children: A Great Britain Population Based Study. Plos One. 2011;6(7):e22179

22. Itoh M, Tomio J, Toyokawa S, Isojima T, Kitanaka S, Kobayashi Y. Vitamin DDeficient Rickets in Japan. Global Pediatric Health. 2017;4:1-5.

23. Naugler C, Zhang J, Henne D, Woods P. Hemmelgarn BR. Association of Vitamin D status with socio-demographic factors in Calgary, Alberta: An ecological study using Census Canada data. BMC Public Health. 2013;13(1):1-10.

24. Munasinghe LL, Yuan Y, Willows ND, Faught EL, Ekwaru JP, Veugelers PJ. Vitamin $\mathrm{D}$ deficiency and sufficiency among Canadian children residing at high latitude following the revision of the RDA of Vitamin D intake in 2010. Br J Nutr. 2017:117(3):457-65.

25. Hanley DA, Davison KS. Vitamin D Insufficiency in North America. J Nutr 2005:135(2):332-7.

26. Wang S, Jiang S, Xu H, Li MC, Wang Z, Zhang S, et al. Nutrient Status of Vitamin D among Chinese Children. Nutrients. 2017;9(4):319.

27. Foo LH, Zhang Q, Zhu K, Ma G, Trube A, Greenfield H, et al. Relationship between Vitamin D status, body composition and physical exercise of adolescent girls in Beijing. Osteoporos Int. 2009;20(3):417-25.

28. Roh YH, Kim BR, Choi WB, Kim YM, Cho MJ, Kim HY, et al. Vitamin D deficiency in children aged 6 to 12 years: Single center's experience in Busan. Ann Pediatr Endocrinol Metab. 2016;21(3):149-154.

29. Dam RMV, Snijder MB, Dekker JM, Stehouwer CD, Bouter LM, Heine RJ, et al. Potentially modifiable determinants of Vitamin D status in an older population in the Netherlands: the Hoorn Study. Am J Clin Nutr. 2007;85(3):755-61.

30. Gill TK, Hill CL, Shanahan EM, Taylor AW, Appleton SL, Grant JF, et al. Vitamin D levels in an Australian population. BMC Public Health. 2014;14(1):1-11.

31. Braegger C, Campoy C, Colomb V, Decsi T, Domellof M, Fewtrell M, et al. Vitamin $\mathrm{D}$ in the healthy European paediatric population. J Pediatr Gastroentero Nutr. 2013;56(6):692-701.

32. Surve S, Chauhan S, Amdekar Y, Joshi B. Vitamin D deficiency in Children: An update on its Prevalence, Therapeutics and Knowledge gaps. Indian J Nutr. 2017;4(3):167

33. Kapil U, Pandey RM. Prevalence of Vitamin D deficiency and associated risk factors among children residing at high altitude in Shimla district, Himachal Pradesh, India. Indian J Endocrinol Metab. 2018;21(1):178-83.

34. Baidya A, Chowdhury S, Mukhopadhyay S, Ghosh S. Profile of Vitamin D in a cohort of physicians and diabetologists in Kolkata. Indian J Endocrinol Metab. 2012;16(Suppl 2):S416-7.

35. Dhore R, Wasnik V. Vitamin D status of apparently healthy early adolescents in Amravati City of Maharashtra, India. Int J of Collaborative Res on Internal Med and Public Health. 2013;5(9):608-18.

36. Holick MF. High prevalence of Vitamin D inadequacy and implications for health Mayo Clin Proc. 2006:81(3):353-73.

37. Bhagwat S, Gulati D, Sachdeva R, Sankar R. Food fortification as a complementary strategy for the elimination of micronutrient deficiences: Case studies of large scale food fortification in two Indian States. Asia Pac J Clin Nutr. 2014;23:4-11

38. Pilz S, März W, Cashman KD, Kiely ME, Whiting SJ, Holick MF, et al. Rationale and Plan for Vitamin D Food Fortification: A Review and Guidance Paper. Front Endocrinol. 2018;17(9):373.

39. Gupta A. Fortification of foods with Vitamin D in India. Nutrients. 2014;6(9):3601 23.

40. Gupta GA. Fortification of Foods With Vitamin D in India: Strategies Targeted at Children. J Am Coll Nutr. 2015;34(3):263-72.

Article History: Submission Date : 28-11-2020; Revised Date : 09-01-2021; Acceptance Date : 12-02-2021

Cite this article: Sureshkumar A, Nagappan K. A Comprehensive Review on the Prevalence of Vitamin D Deficiency among School-Aged Children around the World. J Young Pharm. 2021;13(1):34-9. 